\title{
An assessment of severe wind hazard and risk for Queensland's Sunshine Coast region
}

\author{
$\underline{\text { R.P. Cechet }}^{\text {a }}$, A. Sanabria ${ }^{\text {a }}$, T. Yang ${ }^{\text {a }, ~ W . C . ~ A r t h u r ~}{ }^{\text {a }, \text { C.H. Wang }}{ }^{\text {b }}$ and X. Wang ${ }^{\text {b }}$ \\ ${ }^{a}$ Environmental Geoscience Division, Geoscience Australia, Canberra, A.C.T., 2609, Australia \\ ${ }^{b}$ Urban Systems Program, CSIRO Ecosystem Sciences, Highett, Victoria, 3190, Australia \\ Email: bob.cechet@ga.gov.au
}

\begin{abstract}
Understanding how regional climate, and the extremes associated with it, will change over the coming decades is a vital step towards effective local adaptation. The understanding of the vulnerability and risk from severe winds is derived from a number of factors, including the frequency and intensity of the hazard, community exposure and the relationship between gust wind speed and impact/loss associated with residential structures. The Australian Government, through the Australian Building Codes Board (ABCB), has responsibility for maintenance of the Building Code of Australia (BCA), which establishes performance requirements that buildings must satisfy when subjected to the actions of, among other hazards, severe winds. The Australian /New Zealand Wind Loadings Standard (AS/NZS 1170.2, 2011) specifies the gust wind speeds used in calculating loads on structures in different regions of the country. Design wind speeds are similar to wind hazard (both described in terms of return period gust wind speeds), and the levels are set in an effort to equalise the risk between the low and high hazard regions across the country. Areas around the northern coastline are subject to the impact of tropical cyclones, and as such are deemed to experience the highest wind hazard. This results in Australia being divided into four regions, within which the wind speed is broadly similar. Regions $\mathrm{C}$ and D are those where the hazard is dominated by tropical cyclones.
\end{abstract}

A recent report "Impact of climate change on design wind speeds in cyclonic regions" (Holmes, 2008) prepared for the Australian Building Codes Board recommended that:

- $\quad$ "Cyclonic wind Region C should be extended south on the Queensland coast to $27^{\circ} \mathrm{S}$. This is justified based on the recent simulation studies on the effects of climate change, and restores the boundary to that in the Standard between 1975 and 1989."

- "The existing uncertainty factor for Region $\mathrm{C}, \mathrm{F}_{\mathrm{C}}$, should be increased to $1.10(+5 \%)$, primarily in response to predictions of increased Category 3-5 cyclones by climate model simulations."

An area where the impact of such regulatory changes would be significant is the Sunshine Coast region in Queensland. Changing the AS/NZS 1170.2 region from B to $\mathrm{C}$ would render most of the existing homes noncompliant, hence increasing the risk by virtue of increased hazard without reduction in vulnerability via adaptation. This study seeks to develop the underpinning science that could be used to evaluate the need for adaptation (re-classification and retrofit of existing housing to comply with revised classification).

Cyclonic wind hazard for the Sunshine Coast region has been estimated using Geoscience Australia's Tropical Cyclone Risk Model, utilising synthetic tropical cyclone event sets derived from observations (1981-2006) as well as IPCC AR4 climate models. The regional wind hazard levels have been modified for terrain, topographic and shielding effects to reflect localised variations in wind hazard. The resulting local wind hazard maps depicting annual exceedence probabilities for severe wind gusts have been integrated with the National Exposure Information System (NEXIS) to provide an analysis of impact, in terms of residential buildings affected and the cost of replacement. Return periods (annual exceedence probabilities) associated with severe wind gust hazard were evaluated for the Sunshine Coast and Southeast Queensland regions for both current climate and future climate scenarios. This wind gust hazard was subsequently used to evaluate annualised loss, which represents the average annual cost to the region of exposure to wind hazard if viewed through a very wide window of time. The costs and benefits of potential changes to wind loading regions for the Sunshine Coast area have been analysed in a Regulation Impact Statement (RIS) prepared by the Australian Building Codes Board (ABCB, 2010). The RIS focuses on changes to standards for new buildings and houses; it does not address the impacts on existing buildings. This study presents analyses of risk for both existing and new buildings considering the variation in structural vulnerability within the building stock.

Keywords: $\quad$ wind hazard, wind risk, risk assessment 


\section{INTRODUCTION}

Climate change is expected to increase severe wind hazard in some regions of the Australian continent with consequences for exposed infrastructure and human populations. Studies of the impact of climate change and cyclones in the Australian region suggest that the frequency of severe tropical cyclones is likely to increase and that in general the southern extent of the region impacted by tropical cyclones may move further south (Leslie et at., 2007; Walsh et al., 2004).

The southeast Queensland region of the Australia continent (Figure 1) is a rapidly growing community comprising the divisions of Brisbane, Gold Coast, and Sunshine Coast, and accounts for around two-thirds $(66 \%)$ of the total population in Queensland (4.5 million approximately). The Sunshine Coast region (northern coastal region of that colored in yellow in Figure 1) stretches from Caloundra to Noosa and is the most rapidly developing division currently with a population around 350,000 people. The region is located south of $25^{\circ} \mathrm{S}$ which is the boundary of the tropical cyclone region as defined by the Australian/New Zealand wind loading standard (AS/NZS 1170.2, 2011). ABCB (2010) considers the extension of the tropical cyclone region to $27^{0} \mathrm{~S}$. This study provides a preliminary assessment of how severe wind hazard and risk is affected by climate change for the Sunshine Coast region and also the Southeastern region of Queensland. This assessment is being undertaken by separately considering wind hazard, infrastructure exposure and the wind vulnerability of residential buildings, and aims to provide a benchmark measure of wind risk for the region underpinned by the National Exposure Information System (NEXIS; developed by Geoscience Australia). The methodology involves the parallel development of the understanding of wind hazard, residential building exposure (in the yellow region shown in Figure 1) and the wind vulnerability of residential structures.

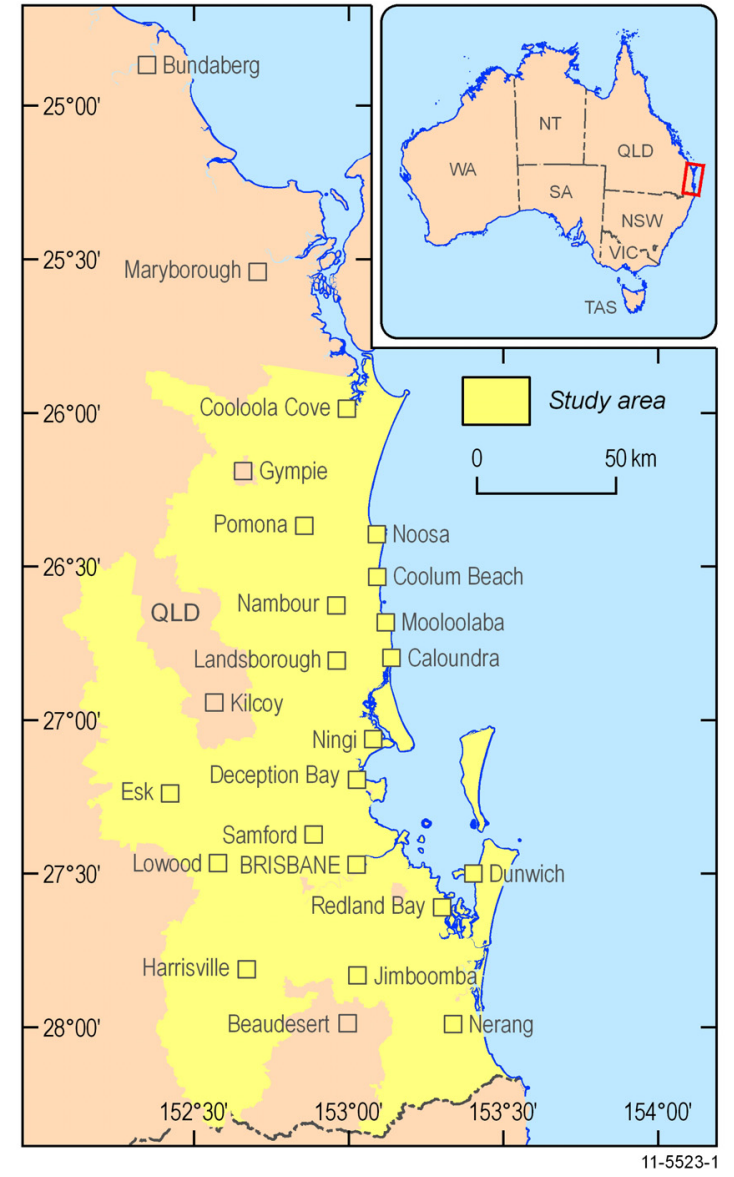

Figure 1. Southeast region of Queensland

\section{METHODOLOGY}

The general methodology applied to risk and impact analyses is a paradigm of "Hazard", "Exposure", "Vulnerability" and "Impact". Each element of this paradigm is required to ensure comprehensive and integrated assessment within a consistent framework. The approach starts with the assessment of severe wind return-period hazard. For each return-period hazard level, the potential for residential building damage is linked to the hazard through the vulnerability relationship for the structure type considered. Damage is calculated through the interaction of wind speed, building exposure and vulnerability.

\subsection{Regional Wind Hazard}

Australian wind hazard is based on the statistical analysis of extreme wind observations and subjective engineering judgment. Observations include peak 3-second wind gusts captured at a small number of meteorological measurement stations, mainly located at significant city and regional airports. These provide a poor spatial representation of wind hazard. The understanding of current regional wind hazard for the Australian continent is in need of improvement and there is also significant uncertainty on how the likelihood and intensity of extreme winds will be influenced by climate change. Geoscience Australia is developing wind hazard models based on simulated data, validated against observations where available. Models providing regional wind hazard for both current and future climate have been developed utilizing separate techniques for the three main wind hazards; tropical cyclones, thunderstorms, and synoptic winds. Regional wind hazard can be considered as the broad-scale low spatial resolution wind hazard, which is derived using 
modelling techniques with a spatial resolution of a few to tens of kilometers. The component wind hazard associated with each weather system (cyclonic, thunderstorm and synoptic) can be combined for each return period (RP) considered, to determine the "combined" regional wind hazard. These models are detailed in Arthur et al. (2010) and Cechet et al. (2011), and they are being further refined as part of an improved estimate of the current climate hazard for Australian wind risk assessment.

\subsection{Local Wind Hazard}

The magnitude of severe wind varies considerably between locations due to differences in terrain, height of the structure, the influence of the surrounding structures and topographic features. Regional hazard assessments do not accurately depict the localized terrain and topography, and therefore the estimates need to be further refined to derive the local wind hazard. For this study, spatial algorithms were developed from the wind multiplier formulae detailed in AS/NZS 1170.2 (2011) and AS/NZS 1170.2 Supp.1 (2002) to estimate the influence of terrain and topography as explained in Lin and Nadimpalli (2005). These algorithms quantify local wind conditions at each location (only urban areas considered). Over city and major town urban regions the wind multipliers were evaluated at high spatial resolution $(\sim 25$ metres $)$ by applying satellite remote sensing techniques, GIS software and digital elevation datasets in conjunction with the formulae.

\subsection{Exposure}

Fundamental to any risk assessment is an understanding of exposure. Building type, construction (roof and wall) type, building age, number of storeys, and replacement value and the spatial location of buildings are critical parameters for understanding the potential impact on Australian communities from various hazards. The National EXposure Information System (NEXIS; Nadimpalli et al., 2007) provides a nationally consistent exposure catalogue at the building level. NEXIS enables the assessment of loss associated with wind hazard given the vulnerability of a particular structural type. The NEXIS residential exposure catalogue is used to determine the location and value of residential buildings "exposed" to the severe wind hazard. The value of the housing is a function of house size and construction type.

\subsection{Wind Vulnerability}

Vulnerability relates the capacity of the buildings to withstand hazards (relates damage to hazard for a specific building type). The vulnerability of buildings to damage caused by severe wind is normally described by an S shaped curve relating damage index (defined as repair cost / building replacement cost) to the 3 second gust wind speed at 10 metre height at the building's location. Geoscience Australia has developed a suite of wind vulnerability models based on heuristic (empirical) principles for application on a wide variety of residential building types in Australia to severe wind. The Australian residential building stock was categorized on the basis of region, age, roof material and wall material. For the modern housing types, a design wind speed was assigned from "Wind loads for housing" (AS 4055, 2006). This approach to vulnerability curve development involved members of the Australian wind engineering community assigning vulnerability curves from a standard suite of curves to a detailed categorization of Australian housing types. The selection of heuristic curves presented for assignation had been calibrated with some post cyclone damage information (TimberEd Services, 2006). The survey responses were averaged to obtain a heuristic vulnerability curve for each category. More information regarding the vulnerability curve development is available in Cechet et al. (2011).

\subsection{Impact/Loss and Risk calculations}

For each return-period hazard level, the potential for residential building damage is linked to the hazard through the vulnerability relationship for the residential structure type under consideration. Damage is calculated through the interaction of wind speed, building exposure and vulnerability. The value of the loss calculated is the full cost of repair or replacement ("new for old"). This is significantly greater than the insured value where payout is often on a "like for like" basis. The method being used to calculate the costs of damage assesses the return period of exceedance loss levels (10 to 2000 years) aggregated to the statistical local area (SLA) region. Losses for individual properties were regressed to obtain a Probable Maximum Loss (PML) curve ${ }^{1}$ and these results were aggregated to each SLA region. The losses represented by the curve range from frequent minor losses through to those associated with catastrophic events. Annualised loss, which is evaluated by integrating the area under the PML curve, represents the average annual cost to the region due to exposure to the hazard viewed through a very wide window of time (2000 years adopted).

\footnotetext{
${ }^{1}$ The PML curve relates damage of a population of similar structures (structural types) to the likelihood (return-period) for the hazard.
} 


\section{RESULTS}

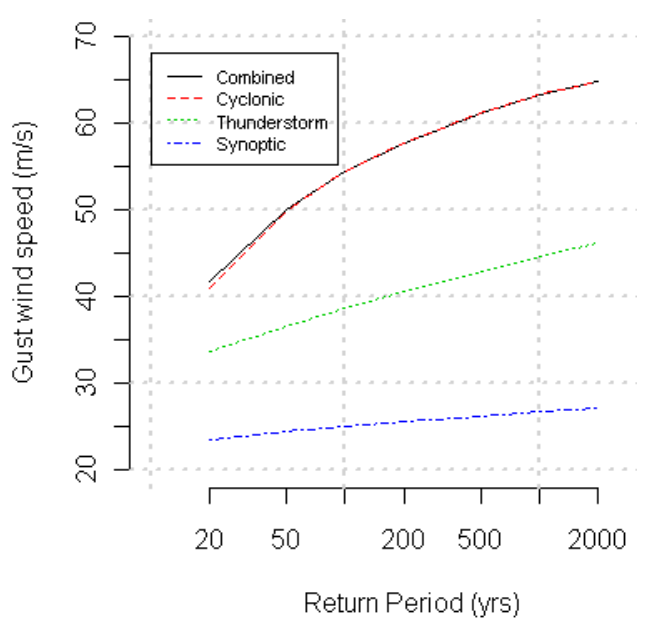

Figure 2. Component and combined regional wind hazard (modelled) for the Sunshine Coast region of Southeast Queensland.

The regional wind hazard (3-second gust at 10 metre height) for the Sunshine Coast region is dominated by the cyclonic hazard component (see Figure 2). The observed regional wind hazard for the Southeast Queensland region is available for three wind observing sites located at Brisbane and Amberley airports and at Cape Moreton. Figure 3 shows that the observed wind hazard for these three locations is less than the hazard depicted in the wind loading standard (AS/NZS 1170.2). The observed wind record for the Brisbane region is short $(\sim 50$ years $)$ and the hazard assessment is dependent on a small number of extreme wind measurements; the gust wind record for the Sunshine Coast region commenced in 1994. The modelled cyclonic wind hazard for the Sunshine Coast and Brisbane regions (Figure 3) uses a statistical deterministic model to derive a synthetic record that is representative of a much longer timescale. An area of $0.75 \times 0.75$ degrees over each of the regions has been considered. Figure 3 shows that the modelled wind hazard (current climate) for the Sunshine Coast appears to be about $5 \mathrm{~m} / \mathrm{s}$ higher than that for AS/NZS 1170.2 (at 500 year return period utilised in wind loading for residential structures). The Brisbane region modelled hazard is similar to AS/NZS 1170.2 levels. Figure 4 shows the wind hazard (modelled) for the Southeast Queensland region current climate and A1FI scenario (2050 \& 2090) which appears insensitive to increasing greenhouse gases and remains at the hazard level depicted in AS/NZS 1170.2 (Region B). The modelled regional wind hazard for the Sunshine Coast is above AS/NZS 1170.2 (Region B) for current climate (shown) and also for the climate change scenario considered.

Figure 5(a) shows the expected loss (\% of replacement cost) for the 500 year return period hazard (i.e. BCA design event) utilizing the modelled current-climate hazard for the SLA regions within the Southeast Queensland region. The Sunshine Coast region (northern coastal section of area considered; see Figure 1) displays the highest loss due to the higher hazard values. Inland of this coastal region the expected loss is even greater due to the chiefly older and more vulnerable building stock in this region. The Gold Coast hinterland region (far southern region of the area assessed and inland of the coast also displays higher expected loss due to a combination of the topographic forcing of the hazard and a greater proportion of older and hence more vulnerable building stock. Figure 5(b) displays the corresponding annualized loss for the 
Southeast Queensland region which shows a similar outcome with the Sunshine Coast (northern coastal region) and the Gold Coast hinterland displaying significantly elevated values compared to the major population centers of Brisbane and the Gold Coast (considers all events from 10 to 2000 year return period).
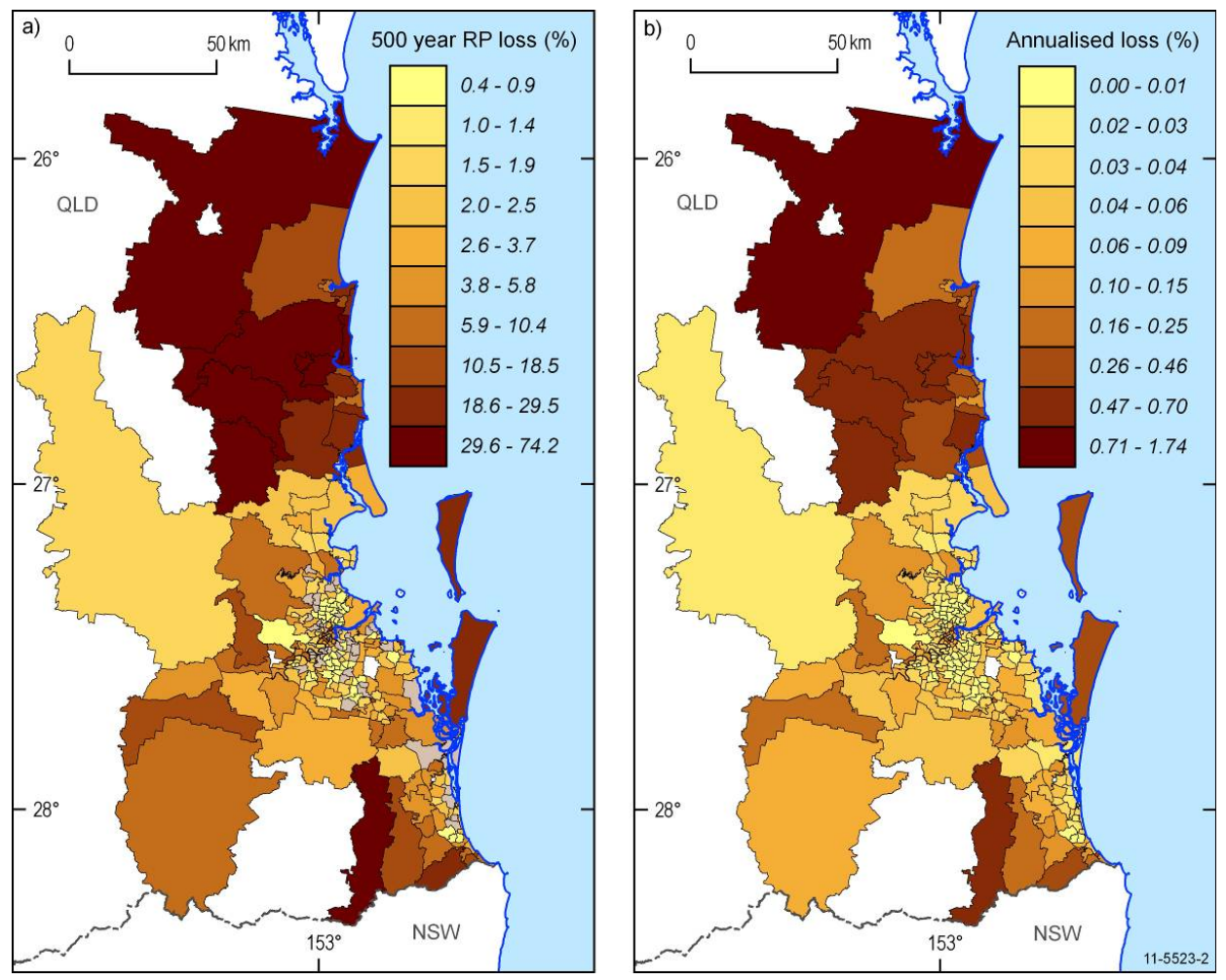

Figure 5. (a) Expected loss (\% replacement cost) for the 500 year return period wind gust hazard (modelled; current climate) for the SE Queensland region; (b) Annualised loss (\% replacement cost) for the SE Queensland region (modelled; current climate).

The risk from severe wind events influenced by climate change scenarios was assessed by considering a range of greenhouse gas emissions scenarios from the Special Report on Emission Scenarios (SRES) which were applied in the Intergovernmental Panel on Climate Change (IPCC) Fourth Assessment Report (AR4). The assessment of future losses was based on the revised estimate of the severe wind hazard derived from AR4 climate model output. Results for the highest emissions scenario (A1FI) are presented in Table 1, and results for all scenarios are provided in Cechet et al. (2011). Projections of population at future times were derived from the Australian Bureau of Statistics (ABS) population projections (2008), providing guidance on the numbers of exposed buildings. Changes in vulnerability due to building decay and the replacement of legacy houses with modern code-compliant buildings were not considered. Societal changes have a dramatic impact on the change in losses, when evaluated in dollar terms. As an indication of the effect of population growth, the numbers of buildings are also presented in Table 1. By 2100, the numbers of buildings have doubled. Even if there was no increase in the loss as a fraction of replacement cost, the increase in building numbers means the dollar losses will be doubled.

Table 1. Annualised loss for severe wind (\% of replacement cost) for the Sunshine Coast and Southeast Queensland regions considering the following sources of regional hazard (wind loading standard [AS/NZS 1170.2], modelled hazard for current climate and for SRES A1FI scenario at 2050 and 2090) and applying ABS Series B population projections. Total number of buildings for each region are shown in parentheses.

\begin{tabular}{|c|c|c|c|c|}
\hline Region & AS/NZS 1170.2 & $\begin{array}{c}\text { Modelled } \\
\text { (Existing conditions) }\end{array}$ & $\begin{array}{c}\text { Scenario A1FI } \\
(2050)\end{array}$ & $\begin{array}{c}\text { Scenario A1FI } \\
(2090)\end{array}$ \\
\hline \multirow{2}{*}{ Sunshine Coast } & $0.588 \%$ & $0.458 \%$ & $0.274 \%$ & $0.222 \%$ \\
$(177,031)$ & $(217,074)$ \\
\hline \multirow{2}{*}{ Brisbane } & $0.172 \%$ & $0.030 \%$ & $0.026 \%$ \\
$(102,963)$ & $(1,078,394)$ & $0.050 \%$ \\
Gold Coast & $(681,045)$ & $(681,045)$ & $0.059 \%$ & $(283,912)$ \\
\hline \multirow{2}{*}{ Southeast Queensland } & $(146,263)$ & $0.086 \%$ & $0.066 \%$ & $0.055 \%$ \\
& $(146,263)$ & $0.104 \%$ & $(1,490,960)$ & $(1,774,788)$ \\
\hline
\end{tabular}




\section{DISCUSSION}

For modeled current climate the aggregated annualised loss (wind risk) for the Sunshine Coast region is an order of magnitude greater than for the Brisbane region and five times that of the Gold Coast region. When considering the "high end" climate change projection (A1FI), the risk decreases for all regions mainly driven by the higher number of buildings that are compliant to the current building standards (all new buildings compliant to current building codes; no allowance has be considered for building deterioration). In general for future climate there is a decline in the risk for the whole of the Southeast Queensland region, but an increase in losses at long return periods (greater than 500 years). This reflects a decline in the frequency of severe events, but an increase in the intensity of the most intense events. This is qualitatively similar to the consensus on global tropical cyclone activity (Knutson et al., 2010), where globally tropical cyclone frequency is expected to decline, but the proportion of intense tropical cyclones is likely to increase. It should be noted from Table 1 that annualized loss (wind risk) derived for the Sunshine Coast region in 2090 (under the A1FI scenario) utilizing this methodology remains much higher than that existing today (current climate conditions) in both the Brisbane and Gold Coast regions. There have been concerns expressed about the level of vulnerability and risk in the Brisbane region following the damage from severe thunderstorms in 2009.

The risk assessment process contains a significant number of assumptions which pose limitations on the use of the derived information. There are a range of issues associated with the modelled hazard and computational methodology as well as issues surrounding climate and population projections. The hazard modelling methodology is an emerging science which requires further. There are major concerns over the intensity and spatial nature of tropical cyclones and thunderstorms. Of particular note is the relatively short length of quality "satellite era" observed record (1981-2006) of tropical cyclone characteristics (track, size, intensity) that is considered by the statistical deterministic cyclone model used here for evaluating cyclonic hazard for current climate conditions. A systematic evaluation of the long-term tropical cyclone landfall record in eastern Australia (Callaghan and Power, 2010) found a long-term trend of much fewer landfalls of intense cyclones (i.e., Category 3, 4, and 5) in the region. They found the existence of a declining linear trend in the number of severe TCs making land-fall over eastern Australia; declined from about $0.45 \mathrm{TCs} / \mathrm{year}$ in the early 1870 s to about $0.17 \mathrm{TCs} /$ year in recent times, representing a decline of approximately $60 \%$ over the full period. Nott and Hayne (2001) describe the recent period of cyclonic activity on Australia's east coast as "unusually quiet for the last few decades". They analysed sand ridges consisting of broken coral formed by severe storms and catalogued the incidence of super-cyclones over the past 5000 years. Their results showed that the frequency of severe-cyclones is an order of magnitude higher than previously thought.

The NEXIS residential database has uncertainty regarding completeness of building age and type classification. In addition, future exposure projections utilising population growth are treated in a simplistic manner. The number of residents per dwelling is maintained as a constant throughout the $21^{\text {st }}$ century and there is no expansion of the current urban footprint (i.e. the increased population is contained in the current urban area. For future building vulnerability, we assume no changes to construction methods or to regional wind classifications. We maintain building resilience (strength) at its current level, not accounting for deterioration and lack of maintenance, or for that matter improvement in resilience brought about by renovations and retrofitting to structures. Independent validation of the vulnerability relationships against insurance data for a range of events should be undertaken to fully assess the utility of the vulnerability curves as well as quantifying uncertainties associated with their application.

\section{FURTHER WORK}

Sensitivity studies to explore the range of uncertainty in the tropical cyclone wind hazard model which underpins the wind risk assessment are being considered. Aspects which merit examination include:

- Estimating TC frequency based on the longer term frequency while retaining only track information from the recent time period (1981 onwards). Frequency of events is better observed than the full tracks, and landfall frequency from the early $20^{\text {th }}$ century could be used to determine the basin-wide frequency.

- Modelling each of the ENSO phases separately. ENSO has a significant influence on the frequency and spatial distribution of TC events. The period 1981-2006 has seen more El Nino events, which are associated with reduced TC activity. This would provide a range of potential wind hazard climates.

- Using more complex methods to evaluate genesis distribution and frequency; this would permit a synthetic record of ENSO to be used to inform genesis rates in evaluating the hazard.

Uncertainty estimation in the existing hazard analysis is also essential. A bootstrap resampling process could be applied to the fitting of the synthetic wind records by extreme value statistical techniques to enable the estimation of confidence intervals around the return period estimates. The modelling system has been built with the capacity to apply a number of different boundary layer models, which has not yet been explored. 


\section{CONCLUSIONS}

This study provides a "first-pass" assessment of the risk that peak wind gusts pose to the Sunshine Coast community (residential buildings) under both current climate and also a high emissions climate change scenario. The assessment utilizes newly developed modelling techniques to consider wind hazard and risk for the Sunshine Coast region. The wind hazard for wind loading applications was found to be dominated by the cyclonic wind hazard. The cyclonic wind hazard for the Sunshine Coast region appears to be:

- greater than the design wind speed in the wind loadings standard (AS/NZS 1170.2) for current climate;

- insensitive to increasing greenhouse gas emissions (high emissions SRES A1FI scenario considered). The "current climate" level of wind risk for the Sunshine Coast region is significantly greater than that for the nearby Brisbane and Gold Coast regions. For future climate (high emissions A1FI scenario) the wind risk reduces in all regions resulting in the risk for the Sunshine Coast for 2090 still being much greater than the present day risk level for the Brisbane and Gold Coast regions. However, significant uncertainty exists regarding the future level of cyclonic hazard for the region. Issues with the input data associated with the cyclonic wind hazard model have been discussed along with a methodology for further work refining the hazard assessment for the region. The analysis presented here provides the first iteration of what will be a continuously improving wind hazard and risk products. The development of an improved understanding of current and future climate hazard and risk will be crucial to informing climate change adaptation options for the Sunshine Coast region regarding severe winds. The results will be of significant concern to decisionmakers in building codes, planning, construction, emergency services, and the insurance industry.

\section{ACKNOWLEDGMENTS}

This study was co-funded by the CSIRO Climate Adaptation Flagship and forms part of the natural hazard research associated with the Southeast Queensland Climate Adaptation Research Initiative (SEQCARI).

\section{REFERENCES}

ABCB (2010). Consultation Regulation Impact Statement (RIS 2010-01) - Construction in Cyclone affected areas, $142 \mathrm{pp}$ Available online at http://www.abcb.gov.au.

Arthur, W. C. Thomas, C. M., Sanabria, L. A. and Cechet, R.P. (2010). Reassessment of wind hazard in the current climate. Proc. of 14th AWES Workshop, Canberra, August 5th \& 6th

AS 4055 (2006). Wind loads for housing, Australian Standard, Available at http:/www.saiglobal.com/PDFTemp/Previews/OSH/as/as4000/4000/4055-2006.pdf

AS/NZS 1170.2 (2011). Structural design actions, Part 2: Wind actions, Australian/New Zealand Standard

AS/NZS 1170.2 Supp 1, (2002). Structural design actions-Wind actions-Commentary, Aus/NZ Standard

Callaghan, J. and Power, S. (2010). A reduction in the frequency of severe land-falling tropical cyclones over eastern Australia in recent decades. Climate Dynamics, DOI 10.1007/s00382-010-0883-2.

Cechet, R.P., Arthur, W.C., Divi, C.B., Dunford, M. Sanabria, L.A., Thomas, C.M., Wehner, M. and Yang, T. (2011). National Wind Risk Assessment (NWRA): Technical Report. GA Record. GeoCat \# 72970

Holmes, J.D. (2008). Impact of climate change on design wind speeds in cyclonic regions, JDH Consulting report for the Australian Building Codes Board (available at www.abcb.gov.au)

Leslie, L.M., Karoly, D.J., Le Plastrier, M. and Buckley, B.W. (2007). Variability of Tropical Cyclones over southwest Pacific Ocean using High-Resolution Climate Model, Meteor. and Atmos. Physics, 97, 171-180

Lin, X.G. and Nadimpalli, K. (2005). Natural Hazard Risk in Perth :Chapter 3: Severe Wind Hazard Assessment in Metropolitan Perth, Geoscience Australia Report, GeoCat No. 63527

Knutson, T. R., J. L. McBride, J. Chan, K. Emanuel, G. Holland, C. Landsea, I. Held, J. P. Kossin, A. K. Srivastava, and M. Sugi (2010). Tropical cyclones and climate change. Nature Geosciences, 3, 157 - 163

Nadimpalli, K. Edwards, M. and Mullaly, D. (2007). National Exposure Information System (NEXIS) for Australia: Risk Assessment Opportunities (MODSIM 2007; International Congress on Modelling and Simulation. Oxley, L. and Kulasiri, D. (Eds)) 1674-1680

Nott, J. and Hayne, M. (2001). High frequency of 'super-cyclones' along the Great Barrier Reef over the past 5,000 years, Nature, $413,508-512$

Timber Ed Services (2006). Report on Wind Vulnerability Research Workshop 14,15 March, 2006

Walsh, K.J.E., K.-C. Nguyen and McGregor, J.L. (2004). Fine-resolution regional climate model simulations of the impact of climate change on tropical cyclones near Australia. Climate Dynamics, 22, 47-56

(C) Commonwealth of Australia (Geoscience Australia) 2011.

This publication is provided under a Creative Commons Attribution 3.0 Australia License with the permission of the CEO of Geoscience Australia. 